\title{
Systemic nature of, and diversification in systems exposed to, flood risk
}

\author{
R. Khatibi \\ Principal Environmental Scientist, Cascade Consulting \\ (Environment and Planning) Limited, Swindon, UK
}

\begin{abstract}
The landscape of flood risk is being populated by applying the risk concept to a wide range of flood management systems against a background where rethinking is driving the shift from flood defence to flood risk management. This is in a background, where tools, concepts, systems and applications are diversifying by adapting to varying complexities. It is concerning that inherent interconnections are overlooked among systems exposed to flood risk from different sources. This paper aims to stimulate debate on interconnectivity among systems with exposures to flood risk, refers to this as the systemic flood risk, and recognises some reciprocity between interconnectivity and diversity.
\end{abstract}

Keywords: flood, risk, systemic, diversity, descriptive-quantitative risk model.

\section{Introduction}

Sources and pathways giving rise to flooding are wide, including pluvial inflows to sewer systems; fluvial flows to natural conveyance river systems; and tidal and storm surges giving rise to coastal and estuarial inundations. These sources and pathways were often studied on their own but the summer 2007 floods in the UK showed that this is no longer tenable and these sources of flooding should be considered together. For instance, the Pitt Report [1] states "They're all pointing the finger at each other, saying you're responsible - one party's blaming another." This signifies the need for considering the various sources of flooding and their collective impacts. The paper focuses on the interconnection among systems exposed to flood risk, and refers to this as the "systemic" flood risk.

The timeline in the evolution of the concept of flood risk shows a series of generic steps, each of which would have a bearing on the systemic nature of 
flood risk and some are outlined in this paper. The focus is on current issues, particularly on the role of interconnection among systems exposed to flood risk and on impact of diversification on such interconnections. Diversification of risk methodologies is generally regarded as the strength of this concept and this is true. However, it invokes an unwitting notion that there is hardly any interconnection from one discipline of risk, say flood management, to another, such as socio-economic risks; or from one field of risk, say, fluvial flood risk, to others such as pluvial flood risk. The classic definition of risk, in terms of likelihood of a hazard and consequences, makes this unwitting notion more likely. This stems from not reflecting on processes from hazard to consequence. The paper aims to stimulate debate on (i) promoting the integration of various risk models by uncovering interconnections among the diversifying systems exposed to flood risk; (ii) taking a systemic view of flood risks at a background with tendency towards diversification.

\section{Overview of the emergence of the concept of flood risk}

An overview of evolutionary steps in flood risk management is outlined.

\subsection{Historic background}

Prior to the Industrial Revolution, settled societies normally avoided living in floodplains as the consequences of recurrent floods made a long-lasting impression. So with the benefit of the hindsight on risk, the mindset on flood risk then was evidently based on avoiding areas with recurrent floods but developing in areas with low flood recurrence, rendering low consequences. Figure 1, depicts the mindset of settled societies prior to industrialisation, which may be considered as the cognitive basis for flood risk awareness of the times then.

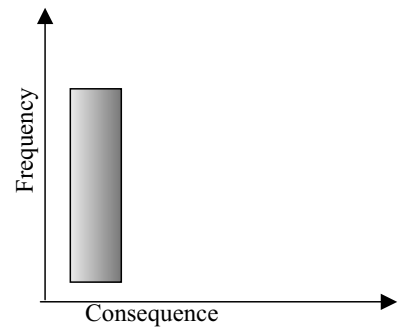

Figure 1: Low frequency-low consequence.

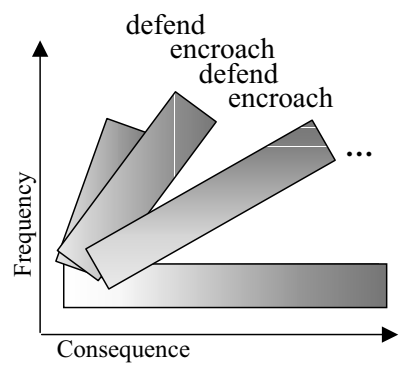

Figure 2: $\quad$ Low frequency-high consequence.

Through the Industrial Revolution, old cognitive values were pushed back and cheap floodplain lands were proclaimed for development by defence works created through inanimate industrial powers. Khatibi and Haywood [2] argue that flood defence was in tandem with utilitarian values of the time, morally justifying an action if produced at least as much good (utility) for all the affected 
people. Flood defence reduced flood frequency but when this was ineffective, driven by high consequences, defences were stepped up. This released more land for development but entailed escalated impacts through a cycle of defend and encroach (develop) as depicted in Figure 2. This process is referred to as the positive feedback mechanism and characterises the mindset of industrial societies in terms of devising flood defences at the expense of escalating consequences. This was typical in other disciplines, e.g. environmental risks.

The mindset of flood defence was brought into focus by high consequences of floods recurrent at a national or regional scale. This paved the grounds for the movement to the uptake of the concept of flood risk in the last 15 years or so, and led to a critical understanding on escalating consequences. Convincing evidence was provided by a Defra commission [3] that the past flood defences prove expensive in the long-run, as annual average economic costs of damages with no defence would be $£ 3 \mathrm{bn}$; but existing standard of defence reduces annual average economic damages to approximately £0.6bn. However, investments have to increase by $£ 128 \mathrm{~m}$ per annum to maintain existing standards. Similar evidences were produced in other countries paving the ground for adopting the mindset of risk-based decision-making tools to reestablish the balance between maintenance costs, flood frequencies and reducing risk, a process which may be referred to as the negative feedback mechanism.

Since 2000, a wide range of research has been carried out to make systems at risk of flooding sustainable involving permanent structural flood defences, development control, the use of temporary and demountable systems, a provision of flood forecasting and warning services and other soft measures such as managed retreat or insurance. The timeline of some of these measures are shown in Figure 3 and their main features include: collectively they represent the mindset of sustainable development through risk management measures, which are prevailing worldwide; the functions of these measures are often complementary; and each measure has diversified.

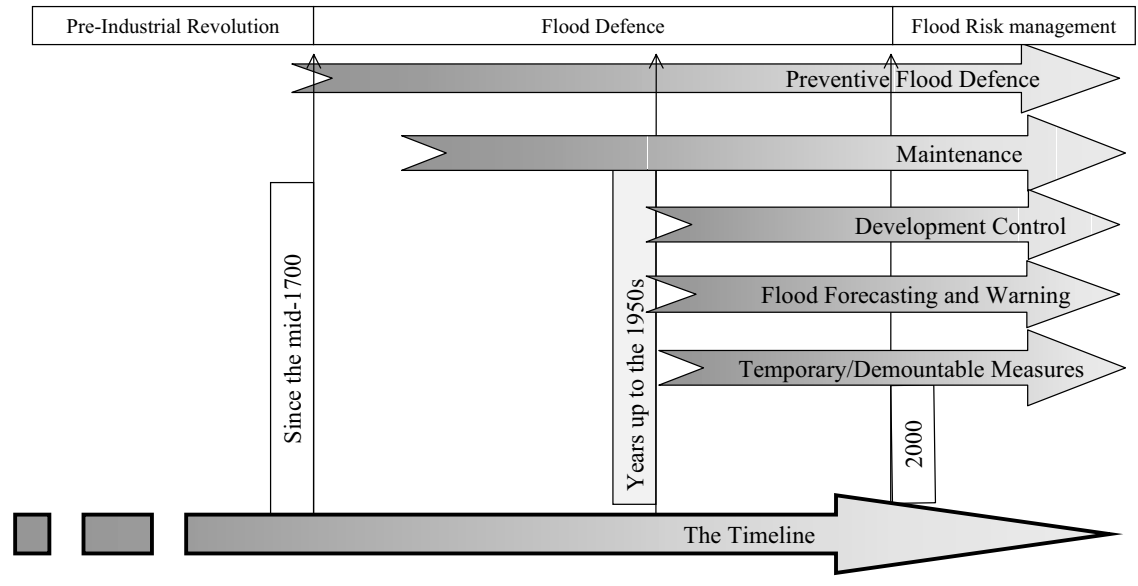

Figure 3: Timeline of key flood risk management measures. 


\subsection{Conceptual risk models}

Conceptual models commonly used to study risk comprise: a quantitative model and a descriptive model. The quantitative model of risk is expressed in terms of likelihood of a hazard and its consequences. Some authors include vulnerability as another factor or risk dimension, e.g. Gendreau et al. [4] but this will be reviewed later in the paper.

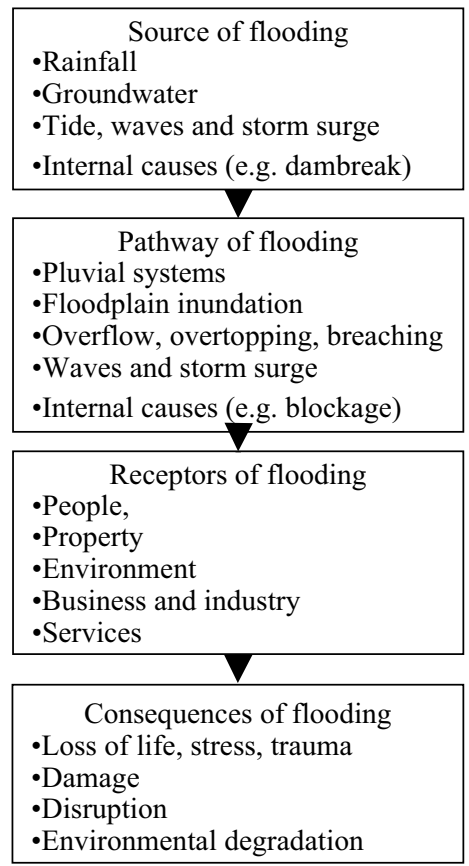

Figure 4: Descriptive flood risk model.

The descriptive risk model, as illustrated in Figure 4, addresses the processes of risk evolving through Source, Pathway, Receptor, and Consequence ( $S-P-R$ $C)$. This model is believed to have been presented originally by DETR [5] and now it is commonly adopted to represent systems and processes that lead to a particular consequence. For an operational risk to arise, there must be a hazard that consists of a source or initiating event; a receptor (person or property); and a pathway that links the receptor to the source. Consequence of flood risk exposure may include loss of life, stress and trauma, or damage to property or business, as well as disruption to services.

\subsection{Emerging issues}

Traumatic experience of flood victims plus damages and loss of life may not warrant calling flood risk as systemic but the domino effect experienced during 
the summer 2007 floods, for which evidence is cited below, goes some way to argue for a systemic nature to flood risk. This term is used in other risk areas such as offshore technology and in financial litigation. For instance, Kaufman and Scott [6] review the definitions of systemic risk in financial litigation and cite one definition as "systemic" refers to an event having effects on the entire banking, financial, or economic system, rather than just one or a few institutions" (Bartholomew and Whalen [7]. They cite another definition: systemic risk is the risk of a chain reaction of falling interconnected dominos" (Kaufman [8]).

Floods of summer 2007 in the UK might have been caused by extreme meteorological events or might have been a direct consequence of climate change, but they clearly showed that floods from different sources could interact. A detailed review of the event given in the Pitt review shows that:

- Rivers overtopping to flood surrounding areas (river or fluvial flooding) interacted with direct flooding of areas with insufficient drainage capacity (surface water or pluvial flooding).

- Surface water flooding was unprecedented, for which prediction tools were often limited and there was no significant warning capability.

Summer 2007 events triggered another rethinking in the UK on flood risk management involving the criticality of the assets (which this paper is not concerned with) and interactions between different sources and pathways of flood risk, reminiscent of systemic risks. For instance, the Pitt report [1] states that "the widespread nature of the flooding had startling, major and unexpected impacts on infrastructure leading to the loss of essential services." The report describes the case of a flooded water treatment works, Tewkesbury, Gloucestershire, which left 350,000 people without water across the county - the most significant loss of essential services since the Second World War. Other loss of services included the shutdown of a number of major and secondary electricity sub-station, leaving some 200,000 people without power. Hundreds of sewage treatment works and pumping stations failed, causing local pollution in flooded areas. A dambreak problem was imminent but was just avoided. These risk exposures were on top of loss of life, damage, disruptions to transport networks and stranding people to a halt in roads, motorways and Railway networks.

In order to understand systemic complexities, it is essential:

- To understand diversity and concept variations in systems exposed to risk;

- To gain an insight into the processes leading to the exposure of flood risk;

- To visualise interconnected systemic risks from sources to consequences.

\section{Diversity in flood risk systems and variations in flood risk products}

Variation and evolution are common features of flood risk management systems, without understanding of which an insight into systemic flood risk is not possible. The diversity of systems exposed to flood risk stems from: (i) each locality would include land drains, highway drainage, urban sewerage systems, river drainage systems and possibly estuaries and coastlines; (ii) each would 
adapt to local conditions by being retrofitted with new regulatory and adaptive measures; (iii) each would interact with others at one or more interfaces.

\subsection{Examples of variations - the definition of flood risk}

Whilst there is a wide agreement in the definition of flood risk in terms of likelihood of a hazard and its consequence, one source of variation is caused by the inclusion of vulnerability in the definition. Consider the following:

1. As outlined above, Gendreau et al. [4] consider risk as the product of hazard and vulnerability (sensitivity to land use). They argue that we practically never speak about flood risk in alluvial forests or at hill tops. Alluvial forests are regularly flooded (hazard) but with no prejudicial consequences; and whatever the vulnerability at hill tops, flooding would never occur.

2. Rouhban [9] considers risk as the product of vulnerability and hazard, where vulnerability is due to societal factors e.g. disintegration of social patterns, environmental degradation, ineffective institutional structures, certain beliefs/customs, limited access to political power.

3. Green [10] relates vulnerability to the challenge versus the coping capacity of the human systems. So, either the challenge is reduced or the coping capacity of the human systems is enhanced by, for example, providing flood warnings and flood refuges. Vulnerability encourages the consideration of the full spectrum of disturbances in the system instead of thinking about the vulnerability to the physical processes of floods. Also, creating 'resilient' systems means improving the capacity to cope with extreme events.

4. PPS25 [11] defines categories of vulnerability in relation to developmental control, comprising essential infrastructures, water compatible structures, highly vulnerable, more vulnerable, less vulnerable groups.

The traditional definition of risk, in terms of the product of likelihood of a hazard and its consequence, seems to apply to a reactive mode of risk management and that in terms of vulnerability when receptors can be classified proactively. As such, vulnerability can be represented in the descriptive model for assessing flood impacts of any sources and pathways on individual vulnerable group.

Both the challenges and the coping strategies, in recent years and since the summer 2007 floods, have become topical and arguably the use of the descriptive risk model can offer at least as a visual aid to understand both vulnerability and resilience as an integral part of the receptor processes.

\subsection{Examples of evolution - flood risk mapping}

Flood maps convey information to readily define and quantify existing and future flood risks but their information contents are diverse and evolving. In the UK, flood mapping has been evolving as follows:

- Section 24(5) of the Water Act 1973 led to a nationally driven work in the 1980 's on "floodplain surveys" and production of maps known as historical flooding maps recording the maximum extent. 
- There was no statutory requirement for flood mapping until the publication of the Department of the Environment's (DoE) Circular 30/92 'Development and Flood Risk' driven by Section 105 of the Water Resources Act 1991.

- The first concerted effort to map flood risk was reported in 1996 by the IoH showing areas at risk of flooding from extreme events. This map production was made possible by technological advances then to produce a single map or a series of maps with consistent return period. Notably, the outputs were called flood risk map but risk was represented in terms of return period [12].

- The predecessor of the Environment Agency initiated projects to produce Section 105 maps to advice on appropriateness of development.

- Following the 1998 Easter floods, a need was perceived for a flood awareness tool and this led to the production of 'Indicative Floodplain Map' (IFM), first Published on the Internet in 2000 at a national scale in the UK but ignored defences and actual flooding probabilities.

Following the publication of IFMs, the need was conceived for a diversity of maps and after the publication of Policy and Planning Guidance note 25 in 2001 , now the expectation is wide on mapping to cover local details, floodwater depths, possible flow directions, local variations in topography; updateable flood management features; identify vulnerable assets; property-related search information; and climate change impacts. Developments are underway in the UK to better understand the performance of flood defences in terms of "systems" of defences rather than single defences, as in RASP: http://www.rasp-project.net/.

\section{Interconnectivity in systems exposed to flood risks}

There seems to be some reciprocity between diversity of systems exposed to flood risk and their interconnectivity. However, the descriptive risk model can remove this reciprocity by visualising interconnectivities for systemic flood risks, as discussed below and a case is outlined to show the integration of the descriptive risk model to systems of forecasting coastal floods.

\subsection{Interacting floods from different sources/pathways}

Systems exposed to flood risk have diversified with respect to source, pathway, receptor and consequence. The descriptive risk model is often applied with one source of flood risk in mind but can be applied to each source and pathway of flood risk side-by-side and also to lay out groups of vulnerable and resilient receptors appropriate to each flood risk mitigation measure, as in Figure 5:

- Pluvial inflows to land-drains, highway drainage and urban sewers;

- Fluvial flows through various sizes of watercourses and rivers;

- Groundwater inflows into watercourses and rivers;

- Tidal and storm surges flowing into estuaries and along coastlines; and

- Other sources e.g. blockage or dambreak problems by failing reservoirs.

In order to manage systemic risks, it is important to realise that each of these components has its own character, the main features of which are outlined as: 
- Sewer flooding occurs due to insufficient capacity to cope with rainfall volumes; the process is quick and often without necessary lead time to warn.

- Flooding from fluvial flows is normally widespread and due to active research, there is a better understanding for such floods in terms of design, management and flood forecasting and warning.

- Flooding from pluvial sources are in contrast with those from groundwater, which is normally in the form of persistent flows for long durations but floodwater volumes are not as high as from pluvial and fluvial sources.

- The scale of floods from tidal and storm surge sources in the UK is considerable and there is a better understanding of such floods in relation to overtopping, breaching of defences and inundations.
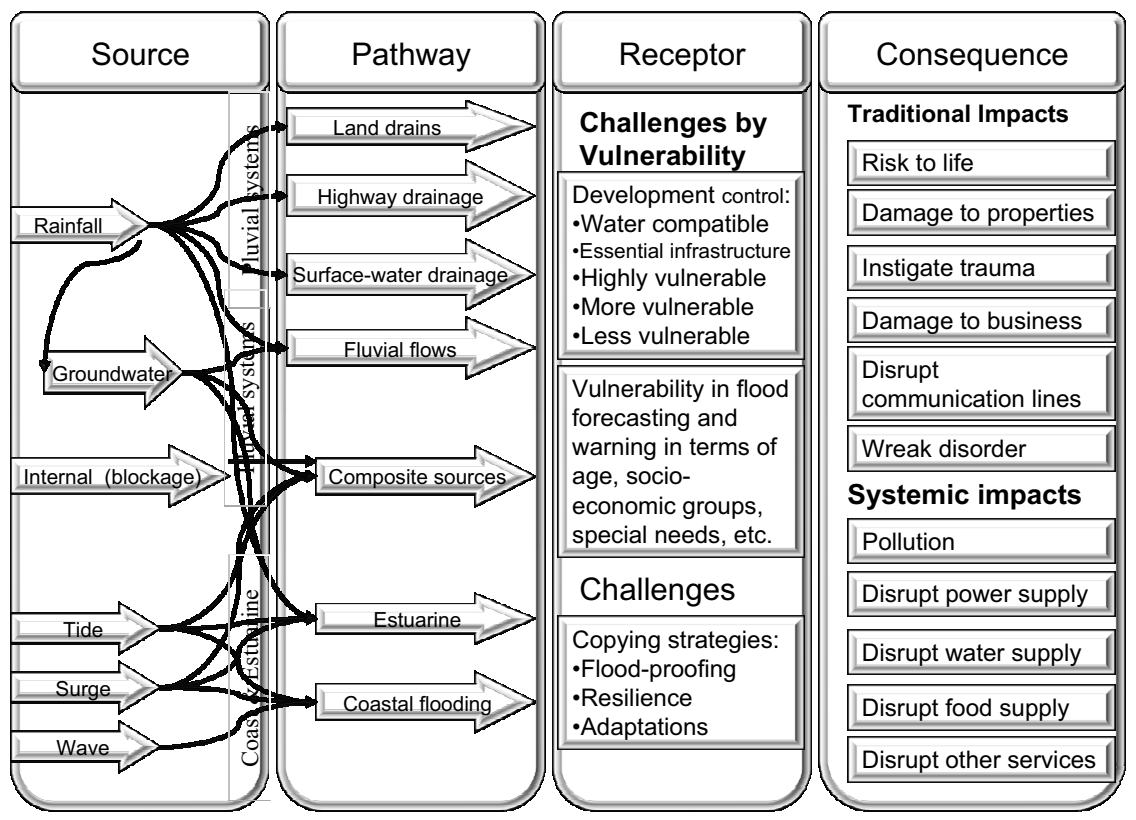

Figure 5: Systemic overview of interconnectivity from various sources of flooding.

Floods from each of these sources are now associated with mitigation measures of their own. For instances, Sustainable Drainage systems (SuDs) promote source control through a raft of measures and a range of hard and soft measures are available for mitigating fluvial floods from each of the sources.

Floods from each of these sources can have an evolutionary path of their own and can interact with other systems depending on the real-time conditions. Interacting floods from different sources/pathways, i.e. systemic risks, are much complex entities than from one source alone as in traditional capabilities. Coping with systemic flood risks would depend on an understanding of the above diversities and their interconnectivities. It is tentatively argued that: 
- The descriptive risk model can be used to visualise systemic flood risks;

- Unlike traditional flood risk limited to loss of life, property and business, systemic risks can undermine vital services through domino effects;

- Systemic impacts may not be a linear sum of the individual impacts but there may be discontinuities in the sense of catastrophe theory [13].

\subsection{Application to coastal flood forecasting and warning}

Flood forecasting and warning is a sequence of systemically arranged processes of detection, flood forecasting, warning, dissemination and response. As the focus on risk is poor in this sequence, Khatibi et al. [14] used the descriptive Source-Pathway-Receptor-Consequence model, to improve on the risk focus, Figure 6. The background for this work was on selecting flood forecasting solutions to particular systems but allowing flood risk to be the driver.

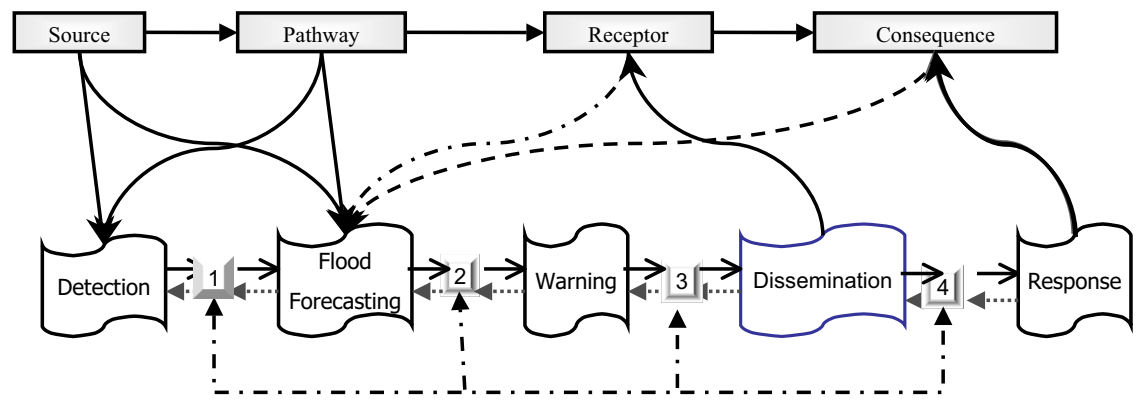

Figure 6: $\quad$ Flood forecasting and warning services.

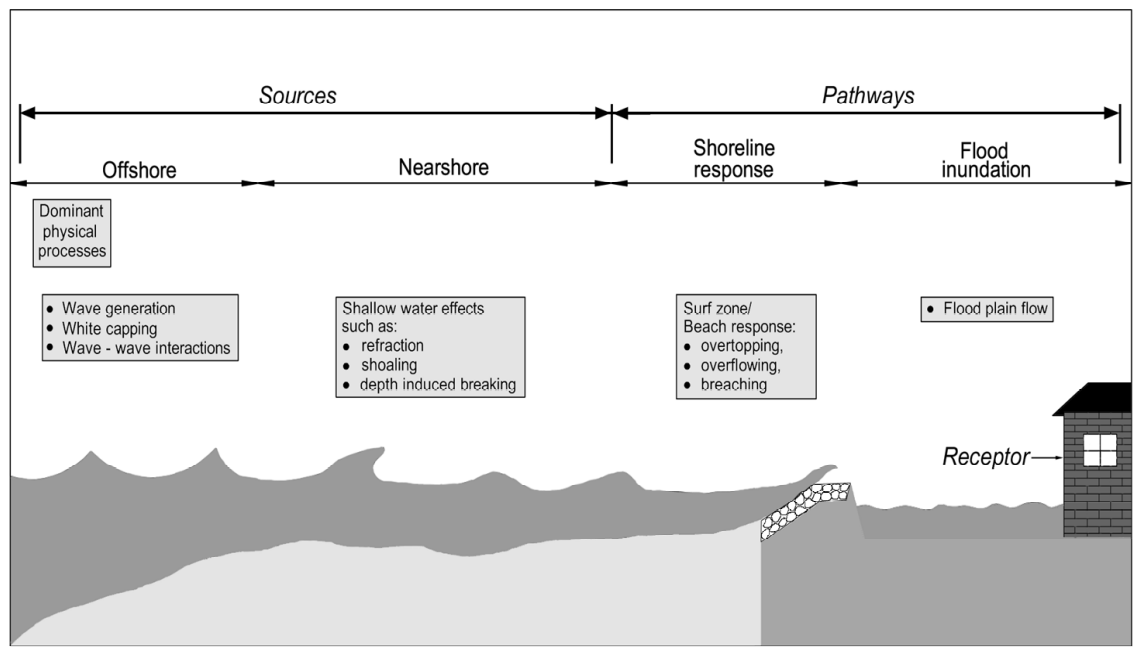

Figure 7: Categorisation of physical systems in coastal flood forecasting into zones. 
In relation to selecting flood forecasting modelling solutions, offshore and nearshore zones are recognised as source; onshore and coastal floodplain as pathways; properties as receptors of flood risk; see Figure 7 . In this way, the risk-driven model selection was integrated into decision-making using predetermined risk levels (high, medium or low) matching model selection with appropriate information content (high, medium or low).

\section{Conclusion}

Being mainly focused on stimulating debate, the paper considers the summer 2007 flooding events as an instance of systemic flood risk exposure, which can be recurrent with the risk of climate change. The summer 2007 events provide ample data to rethink, as one of many such episodes over the years. The paper takes a generic overview of the historic context of floods. It argues that the mindset of settled societies was established on cognitive basis prior to the Industrial Revolution and avoided settlements at high flood frequency areas thus securing low consequences. Instigated by inanimate industrial powers, utilitarian values exploited cheap floodplain and low-lying coastal lands for development by devising flood defence works. Flooding consequences drove the emerging flood protection mindset to a race for more defence and to make more cheap land available for development. The flood defence mindset has been retreating over the last 15 years or so in favour of today's flood risk management mindset.

The paper outlines a preliminary context for the systemic nature of flood risk and argues that the backdrop for this is a diversity of systems comprising manmade drainage, natural water conveyance or coastal systems. As these systems can interact, they can give rise to a domino effect through a series of systems exposed to flooding risk. Thus, ways of understanding their inherent interconnectivity is important and the paper argues that the descriptive risk model can be used as a visualisation tool to understand their interconnectivity.

\section{Acknowledgements}

The author wishes to thank Dr Kieran Conlan, the Managing Director of Cascade Consulting for his support and encouragement for this paper. Gratitude is also expressed to Mr. Trevor Wade, a technical director at Cascade Consulting for his review and comments. This paper aims to stimulate debate and the opinions expressed are author's and do not necessarily represent the company's views.

\section{Reference}

[1] Sir Michael Pitt, Learning lessons from the 2007 floods, an independent review: http://www.cabinetoffice.gov.uk/upload/assets/ www.cabinetoffice. gov.uk/flooding_review/flood_report_web.pdf, 2008. 
[2] Khatibi, R. and Haywood, J. The role of flood forecasting and warning on sustainability of flood defence, Special Edition of Munic. Eng. of the Proc. Inst. Civ. Engrs., Vol. 151, (December 2002) Issue 4, pp 313-320

[3] Defra (2001), National Appraisal of Assets at Risk from Flooding and Coastal Erosion, including the potential impact of climate change, Final Report, http://sciencesearch.defra.gov.uk/Document.aspx?Document= FD2004_1033_TRP.pdf

[4] Gendereau N., Desbos, E., and Gilard, O., (2000), The Inondabilité method, Floodware final report, Cemagref Editions, ENV4-CT96-0293.

[5] DETR, Environment Agency, Institute for Env. Health, (2000), Guidelines for environmental risk assessment and management, ISBN 0-11-753551-6

[6] Kaufman, G.G and Scott, K.E, What is systemic risk and do bank regulators retard to contribute to it, The Independent review, Volume VII, No 3, Winter 2003, http://www.independent.org/pdf/tir/tir_07_3_scott.pdf

[7] Bartholomew, Philip, and Gary Whalen. 1995. Fundamentals of Systemic Risk. Research in Financial Services: Banking, Financial Markets, and Systemic Risk, vol. 7, ed. George G. Kaufman, 3-17. Greenwich, Conn.: JAI.

[8] Kaufman, G.G, 1995a. Comment on Systemic Risk. In Research in Financial Services: Banking, Financial Markets, and Systemic Risk, vol. 7, edited by George G. Kaufman, 47-52. Greenwich, Conn.: JAI.

[9] Rouhban B. (2005), The UN system engaged in disaster reduction, Conference, Speech on Disaster Reduction at King's College London, October 2005: http://www.kcl.ac.uk/content/1/c4/67/52/BadaouiRouhban. pdf

[10] Green, C. Flood risk management in the context of integrated water resource management, http://www.fhrc.mdx.ac.uk/resources/docs_pdfs/ wuhanfin.pdf

[11] PPS25, Planning Policy Statement 25; http://www.communities.gov.uk/ documents/planningandbuilding/pdf/planningpolicystatement 25

[12] Morris, D. G. \& Flavin, R. W. 1996, Flood risk map for England and Wales. Report no. 130, Institute of Hydrology, Wallingford, UK.

[13] Poston, T., and Stewart, I., Catastrophe Theory and its Applications, Pitman, London, 1978. Psychological Bulletin, 111, 375-379.

[14] Khatibi, R., Gouldby, B., Sayers, P., McArthur, J., Roberts, I., Grime, A. and Akhondi-asl A, (2003), Improving coastal flood forecasting services of EA, Proc. of 1st Int. Conf. on Coastal Mng., UK, (Ed. McInnes, R.G.). 